\title{
An Analysis of the Performance of European Union Countries in the Light of Europe 2020 Strategy Indicators
}

\author{
Elena Grimaccia \\ Correspondence: Elena Grimaccia, Istat, Italian National Institute of Statistics, 00184, Rome, Italy. \\ Received: August 5, 2020 Accepted: September 10, 2020 Online Published: September 24, 2020 \\ doi:10.5539/res.v12n4p12 URL: https://doi.org/10.5539/res.v12n4p12
}

\begin{abstract}
In this paper, an analysis of the Europe 2020 strategy indicators has been carried out. The strategy defined three priorities for European countries: Smart, Inclusive and Sustainable growth. These goals (developing an economy based on knowledge and innovation, fostering high employment levels, and promoting a more resource-efficient and greener economy) were measured by eight headline indicators, related to employment, research and innovation, renewables and energy, education and poverty. For each indicator, a target has been set, and the eight indicators are subject to regular statistical monitoring and reporting. Europe 2020 is perhaps not a complete set of indicators for measuring the progress of societies and the quality of life of their citizens, but it is a very important recognition of European institutions that GDP alone is not enough and that it must necessarily be integrated with measures that take into account equity and sustainability. The paper analyses the trends of the Europe 2020 indicators, considering the target reached or not, synthesizing the results using an Alkire-Foster method and clustering the 27 European countries, in order to highlight convergence processes among the Member States (MSs) in the ten years taken into account by the Strategy. After almost10 years, the EU has not reached most of the targets set in 2010, and many MSs are well behind schedule.
\end{abstract}

Keywords: Europe 2020, indicators, development, composite indicators, cluster analysis, European countries

\section{Introduction}

The "Europe 2020 Strategy", proposed by the European Commission, has been adopted by the European Council in 2010 (European Commission, 2010). One of the elements that makes this strategy extremely important is the introduction of a set of indicators equal for all countries to measure the progress of societies and the quality of life of their citizens. The introduction of these indicators follows a long debate within the scientific community around ways of measuring wellbeing that go beyond income at the individual level and GDP at nationwide level (Yu, 2012). Sen (1983, 2000), in particular, argued that multidimensional measures can contribute to identify the broader domains of poverty, not merely its symptoms (i.e. low income). Furthermore, income is better understood as denoting the means to better living conditions, but it is not necessarily the better living condition in itself (Anand and Sen, 1997). This concept can be extended from the individual level to societal level. The debate brought to the constitution of the Stiglitz-Sen-Fitoussi commission that gave a positive appraisal of the multidimensional measures of poverty and well-being. (Stiglitz, Sen, and Fitoussi, 2009). The commission was key to the definition of the indicators that were included in the "Europe 2020 Strategy". The Europe 2020 indicators are not a complete set of indicators for measuring the progress of societies and the quality of life of their citizens, but it is a very important recognition of European institutions that GDP alone is not enough and that it must necessarily be integrated with measures that take into account equity and sustainability (Grimaccia and Rondinella, 2018). The Europe 2020 Indicators have been included in the "GDP and beyond" initiative (European Commission, 2013) and present the characteristics of simplicity and reliability needed to monitor the effects - and probably the causes - of economic crisis on the living conditions of populations.

The ten year strategy defined three priorities for growth in the European countries: Smart growth (developing an economy based on knowledge and innovation), Inclusive growth (fostering high employment, and ensuring social and territorial cohesion) and Sustainable growth (promoting a more resource-efficient and greener economy) (European Council, 2010). To reach these objectives, several benchmarks have been set, and the indicators identified to measure these goals have been and still are subject to regular statistical monitoring and reporting (Eurostat, 2019). In this way, the policy objectives (smart, sustainable and inclusive growth) were declined in measurable, and thus well-defined, numerical targets, making governments "accountable" to the citizens and to the Commission (Rondinella and Grimaccia, 2017). The five targets are currently measured by eight headline indicators, concerning employment, research and innovation, climate change, renewables and energy, education and poverty. These three mutually reinforcing priorities should help the EU and the Member States deliver high levels of employment, productivity and social cohesion (Steurer 
and Hametner, 2013).

This strategy has been developed as a roadmap aiming at restoring the EU's economic growth and stability and it is expected to pursue its international relations and social cohesion (European commission 2010; Ruser and Anheier 2014).

The European Union is a community of great economic potential, but with many problems to overcome. It is composed of 27 countries with different levels of socio-economic development, and analysis of the Europe 2020 indicators would support policies aimed at guarantee sustainable growth (Stec and Grzebyk, 2016).

In this paper, an analysis of the Europe 2020 strategy has been carried out, in order to provide a first evaluation of the European strategy's results. In the analysis of the Europe 2020 indicators, the socioeconomic conditions in which European Countries have reached 2019, differences among the countries, and the pattern towards a smart, inclusive and sustainable growth are presented. In this study, an analysis of Europe 2020 indicators is carried out, in order to show the trends of the eight indicators from the beginning of the Strategy to the most recent data, underlying the convergence (or divergence) processes among European.

The working hypotheses is that over the strategy period there has been no substantial change in the levels and patterns of the Europe2020 indicators in the 27 countries and that the efforts done to reach the targets have been unsuccessful. To understand how the countries have evolved, an analysis of the targets reached by each country is presented. The analysis has been carried out through the study of composite indicators obtained by the Alkire-Foster method (Alkire et al., 2015) The analysis allows to calculate the results achieved by each country and compare it versus the national target and the European one. According to Alkire (2015), a well-being measure might be presumed to be generated not only to satisfy knowledge, but also and perhaps primarily to guide policy, and an adequate well-being measure must: "be understandable and easy to describe; conform to 'common sense' notions of well-being; be able to target the deprived, track changes, and guide policy; be technically solid; be operationally viable; be easily replicable". A composite indicator is formed when individual indicators are compiled into a single index on the basis of an underlying model. It is, therefore, a measure easy to read and compare. Composite indicators have increasingly been accepted as useful and relevant tools for conducting performance assessment and construction of rankings in various fields (Stumbriene et al., 2020).

Finally, the 27 countries members of the European Union in 2020 are grouped by a cluster analysis based on the Europe 2020 indicators, and differences between 2010 and 2019 are highlighted.

The European Union arrived at the Covid-19 pandemic with different levels of development and quality of life among Countries. Analysing these different levels of development could help understanding countries' response to the pandemic and - in due time - it could help understanding the economic and social consequences of the government's' initiatives against the spread of the virus.

\section{Method}

The study is based on the data provided by Eurostat on the eight headline indicators identified to support the Europe 2020 strategy (Eurostat, 2019).

An analysis of the composite indicators constructed based on the Alkire-Foster method has been carried out, taking advantage of the fact that both the method and the strategy are based on well defined benchmarks. The countries are then clustered according to the values of the Europe 2020 indicators at the beginning of the strategy and in 2019.

\subsection{Data}

Europe 2020 is the EU's ten-year growth strategy that puts forward three mutually reinforcing priorities (European Commission, 2010): Smart growth seen as developing an economy based on knowledge and innovation; Sustainable growth, meaning to promoting a more resource efficient, greener and more competitive economy; Inclusive growth that foresees a high-employment economy delivering social and territorial cohesion.

The policy objectives (smart, sustainable, and inclusive growth) were declined in well-defined, measurable, numerical targets. Inclusive growth is monitored by the Employment rate (it should be 75\% of the population aged 20-64 in 2020), and by the number of People at risk of poverty or social exclusion (there should have been 20 million people at risk of poverty less). Smart growth is measured by the share of Early leavers from education and training (that should decrease to under 10\%), by the share of Tertiary educational attainment (that should reach $40 \%$ of the population aged from 30 to 34 years old), and by the Gross domestic expenditure on research and development (R\&D) that should increase to $3 \%$ of the EU's GDP. Sustainable growth: the " $20 / 20 / 20$ " climate/energy targets should be met reducing by $20 \%$ Greenhouse gas emissions (30\% of emissions reduction if the conditions are right), raising the Share of renewable energy by $20 \%$, and enhancing Energy efficiency, reducing energy consumption by $20 \%$. 
In order to raise effectiveness in implementing the strategy, each Member State (MS) has set its own policies and action plans, and periodic reviews of the strategy implementation in terms of realization of its objectives (Barder et al., 2013; Ruser and Anheier, 2014). Most of all, each MS set its own targets, according to their level of development, measured by the eight Europe 2020 indicators. As in Stec and Grzebyk (2016), the EU is not going to achieve its targets if the MSs do not make efforts to reach them.

\subsection{Methods}

In order to combine the results achieved by the MSs, a composite indicator has been constructed. There are a number of different methods to constructing composite indicators, but the most suitable in this case is the MPI by Alkire and Foster (A-F) because it is based on well-identified benchmarks that - in this case - correspond to the targets defined in the strategy (Alkire et al., 2015).

Considering a total of $n$ rows (persons or, as in our case, Countries i), the well-being of each observation is measured in a total of $d$ dimensions $\mathrm{j}$ (columns). The whole dataset is, then, a matrix where each cell represents the achievement level of individual $i$ (from 1 to $\mathrm{n}$ ) in dimension $j$ (from 1 to d). The A-F method foresees to set a deprivation cutoff $z$ for each column. For each dimension, individual $i$ is "deprived" in dimension $j$ if its achievement level is lower than the dimensional cutoff $z$. In Europe 2020 Indicators, the threshold $z$ is institutionally identified: the EU and MS targets are well stated in many documents. A deprivation matrix includes this information, assigning a 1 if individual (or country) $i$ has achieved the goal related to dimension $d$ and a 0 if the country is not "deprived" for that indicator. For each Country, across the row, the positive entries have been added up. No weighting has been applied. Finally, a country could be defined as multidimensionally "not developed" with regard to the Europe 2020 indicators if their "deprivation" score is lower than or equal to the stated cutoff $k$, that in our case is set as the EU27 value.

Cluster analysis is the name given to a collection of algorithms used to classify objects, e.g. countries, species, individuals. The classification has the aim of exploiting the similarities/dissimilarities between cases. The result will be a set of clusters such that cases within a cluster are more similar to each other than they are to cases in other clusters (Fang, 2020). Hierarchical Cluster Analysis (HCA) does not require to pre-specify the number of clusters to be generated. Furthermore, HCA's results can be summed up with a tree-based representation of the observations, called a dendrogram. The difference between the various hierarchical-linkage methods depends on how they define "closest" when comparing groups. The Lance-Williams formula provides the basis for extending the well-known Ward's method of clustering into the general hierarchical-linkage framework that allows a choice of (dis)similarity measures (Murtagh and Legendre, 2011).

In relation to composite indicators, the use of cluster analysis to group countries in terms of similarity between different sub-indicators can serve as: a purely statistical method of aggregation, a diagnostic tool for assessing the impact of the methodological choices made during the construction phase of the composite indicator, a method of disseminating the information on the composite indicator, without losing the information on the dimensions of the sub-indicators, a method for selecting groups of countries to impute missing data with a view to decrease the variance of the imputed values (OECD et al., 2008). Cluster Analysis, thereafter, has been applied to the 27 countries at the beginning and at the end of the ten years length of time of reference, in order to describe similarities (and dissimilarities) of the 27 European countries according to the eight target indicators. More in detail, hierarchical agglomerative linkage clustering has been applied.

\section{Results}

In this Section, an analysis of the Europe 2020 indicators in the ten years considered in the Strategy is presented. Afterwards, the results of the analysis of the composite indexes obtain using the Alkire-Foster method is presented. A cluster analysis of the 27 European countries is finally presented.

\subsection{Europe 2020 Strategy Indicators in the European Union}

The employment target has a key role in the strategy, among education-related targets, and the goal of poverty reduction. For the monitoring of the target, the employment rate of people aged between 20 and 64 was chosen as the key indicator, setting a target of 75 percent. In 2010, the average European employment rate of people aged between 20 and 64 was 6.8 percentage points lower than the target set for 2020. However, this average summarizes strong differences between Member States: some countries, including Sweden, Denmark and Germany, had already reached the target set for 2020, while many others, including Italy and Spain, had differences of more than 10 percentage points with the European target. The increase in the employment rate between 2010 and 2019 has not been as high as it was expected, and the target for the EU as a whole has not been achieved, although some countries (such as Germany and Sweden) have exceeded expectations. Greece, as well as Spain, Italy and France have not achieved the EU target or even their national target.

Research and Development are important components of the Europe 2020 strategy and they contribute to a 
well-functioning knowledge-based economy and industrial competitiveness (Eurostat 2019). R\&D intensity in the EU has grown too slowly to meet the Europe 2020 target, and only four countries have reached the target (Table 1).

Table 1. Number of European member states that have achieved their Europe 2020 targets - 2019

\begin{tabular}{lcc}
\hline & $\begin{array}{c}\text { Number of } \\
\text { Countries that } \\
\text { have achieved } \\
\text { their MS target }\end{array}$ & $\begin{array}{c}\text { Number of } \\
\text { Countries that } \\
\text { have achieved the } \\
\text { EU target }\end{array}$ \\
\hline Employment rate of the population aged 20-64 & 17 & 16 \\
Gross domestic expenditure on R\&D & 4 & 4 \\
Population aged 30-34 having completed tertiary education & 18 & 18 \\
Early leavers from education and training & 15 & 17 \\
People at the risk of poverty and social exclusion & - & 13 \\
Share of renewable energy in gross final energy consumption & 12 & 12 \\
Greenhouse gas emissions, base year 1990 & 12 & 12 \\
Final energy consumption & - & 9 \\
\hline
\end{tabular}

Source: Author's elaboration on Eurostat data.

Closely linked to the objectives relating to the labour market, and to R\&D and innovation is the target related to university education. The target set for the share of graduates between 30 and 34 years for the Union is 40 percent. In 2009 , almost half of the countries of the EU had already reached the target set: some northern European countries (Sweden, the Netherlands, Ireland, Denmark, and Finland) but also France, Belgium, and Spain, had rates close to or above 40 percent. For this indicator, the efforts made by the countries are highly diversified. Some countries like Slovakia set very high targets and reached them. Some countries such as Austria, Czechia and Lithuania have exceeded their very ambitious targets. Thanks to the positive dynamics observed between 2009 and 2019, many other European countries have reached this share. Among these, the Baltic republics and Poland, with progress even over 10 percentage points. Italy, on the other hand, had a fairly low indicator value (19.0 percent) in 2009, ranking fourth last in the ranking of the European Union, and lost further ground, limiting itself to reach 27.5 percent of graduates between 30 and 34 years of age and finishing at the bottom of the ranking.

Decreasing the early school leaving rate to less than 10 percent by the end of the decade is the second goal for education set by the Europe 2020 Strategy. The indicator chosen for monitoring is the share of the population belonging to the age group between 18 and 24 years old who dropped out of studies without having obtained a qualification higher than the upper secondary education diploma (level 3C short of the International Standard Classification of Education - ISCED). The objective has been reached by the EU as a whole and by 15 out of 27 MSs. However, countries like Malta, Italy and Spain present a drop-out rate that is double compared to Sweden, Finland and Slovenia.

Poverty deserves a separate analysis: in Italy, together with Spain, France and Greece, instead of the foreseen reduction of the number of poor people, an increase has occurred.

The part of the Europe 2020 Strategy dedicated to sustainable growth from an environmental point of view identifies specific targets to be reached by the end of the decade: a $20 \%$ reduction in greenhouse gas emissions compared to 1990 levels; the $20 \%$ increase in the share of final consumption from renewable energy; a 20 percent increase in energy efficiency. The target related to GHG emissions has been achieved by the EU27 but only less than a half of the MSs reached the objective of a reduction of emissions to the 80 per cent of the 1990 value. In fact, only some of the main European countries (Denmark, Sweden and Germany) achieved the emissions reduction target, while many others remained above $80 \%$ of 1990 emissions.

Despite the economic contraction related to the crisis occurred from 2008 onward, the reduction in the primary and final energy consumption, until 2018, was not enough to meet the foreseen reduction of 20 per cent in energy consumption has not been achieved by the European Union, and only 9 out of 27 countries met the target.

Neither the target of 20 per cent of renewable energy in gross final energy consumption has been achieved. In the EU27 the share of renewable is stuck at $18.9 \%$ and it is above $30 \%$ only in Sweden, Finland, Denmark, Austria, Latvia, with countries like Netherland below 10\%. All in all, only Denmark, Sweden, Finland and Latvia perform well in all the Environmental sustainability indicators.

\subsection{A Europe 2020 Composite Indicator}

The composite indicator based on the eight Europe 2020 target indicators and constructed according to the A-F method provides a "Europe2020" index for the 27 EU MSs. According to the Europe 2020 development index, a Country is considered as "deprived" or "not developed" if it scores below 3 ( 2 is the EU27 value for the index). The higher the index, 
the higher the number of goals met by the MSs. The fact that MSs could set their own targets added additional divergences among the European countries. Some Countries set very unambitious targets, while others fixed ambitious goals. Therefore, the composite indexes have been constructed using as benchmark both the national and the European targets (Tables 2 and 3). The A-F method allows to summarise the targets reached by Countries, distinguishing between "Low development" (less than 3 goals achieved), "Middle performing" (between 3 and 5 goals achieved) and "High performing" (6 targets achieved or above).

The indexes have been constructed for 2010 and for 2019 (for poverty and environmental indicators data refer to 2018). In this way it is possible to appreciate the development - or not - of the European countries toward the Strategy.

In 2010, a third of the MSs had already achieved more than three targets (Table 2).

Table 2. Europe2020 index (distribution of the composite indicators for the Europe 2020 targets achieved) - 2010

\begin{tabular}{lrrrrr}
\hline & \multicolumn{2}{c}{ EU targets } & \multicolumn{3}{c}{ National targets } \\
\hline $\begin{array}{l}\text { Europe2020 } \\
\text { index }\end{array}$ & Countries & Freq. & & Countries & Freq. \\
\hline Low & 18 & 66.7 & 0 & 18 & 66.7 \\
Medium & 8 & 29.6 & 0 & 9 & 33.3 \\
High & 1 & 3.7 & 0 & 0 & 0 \\
Total & & & & & \\
\hline
\end{tabular}

Source: Author's elaboration on Eurostat data.

In 2019, the number of countries that have achieved a higher number of goals has increased, but a notable share (37\%) presents a low value of the index (Table 3 ).

Table 3. Europe2020 index (distribution of the composite indicators for the Europe 2020 targets achieved) - 2019

\begin{tabular}{lrrrrr}
\hline & \multicolumn{2}{c}{ EU targets } & \multicolumn{3}{c}{ National targets } \\
\hline $\begin{array}{l}\text { Europe2020 } \\
\text { index }\end{array}$ & Countries & Freq. & & Countries & Freq. \\
\hline Low & 8 & 29.6 & 0 & 7 & 25.9 \\
Medium & 14 & 51.9 & 0 & 17 & 63.0 \\
High & 5 & 18.5 & 0 & 3 & 11.1 \\
& & & & & \\
Total & 27 & 100 & & 27 & 100 \\
\hline
\end{tabular}

Source: Author's elaboration on Eurostat data.

Among the best performing countries are Sweden, Finland, Denmark, Netherland Czechia and Latvia.

Austria set very high national targets and did not achieve them but reached 6 out of 8 European targets. Italy, on the contrary, set very low national targets (and score 4 out of 8) but reached only one EU target. No MS reached all the eight targets.

\subsection{European MSs Clustered According to the Europe 2020 Target Indicators}

In order to present the results of the HCA, a graphical configuration is used: a tree called "dendrogram" is an intuitive way to present data clustering when the number of clusters is unknown a priori. Each leaf corresponds to an observation and the branching reflects the relation between clusters.

According to the HCA (Ward method), in 2010, the 27 MSs were grouped into five main groups: the first composed mainly of central European countries, the second given by the Northern Europe MSs with Austria, Portugal and Slovenia (the best performing countries), then the third group is given by Eastern Europe countries, the fourth group is composed of Mediterranean countries, while the fifth and last by Baltic Republic plus Romania. In 2019, the composition of the clusters is not drastically changed, if not for the Baltic Republics that grouped with the Eastern European countries, and for Ireland, Luxembourg, Poland and Cyprus that formed a group separate from the other Countries of Central Europe. 
2010

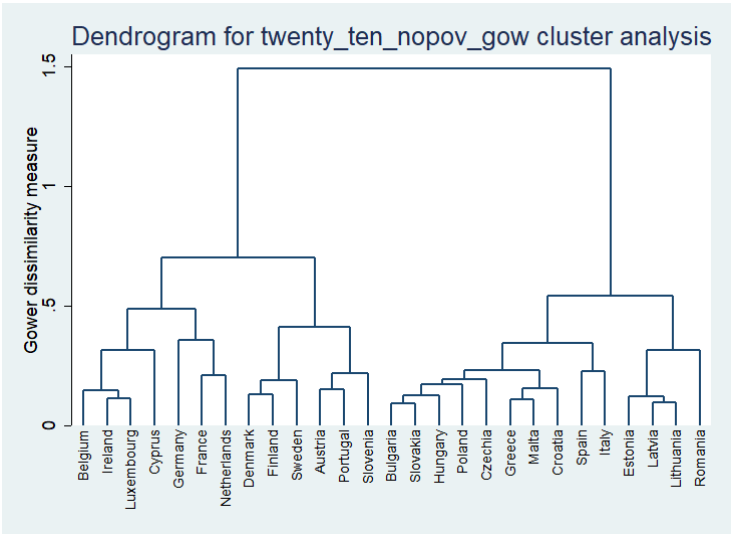

2019

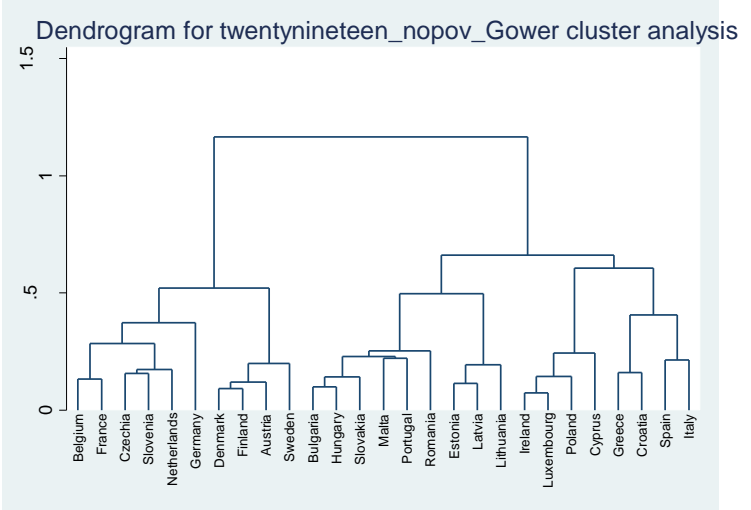

Figure 1. Clusters' dendrograms (Europe 2020 Indicators) - 2010 and 2019

The cluster analysis, thus, indicates that similarities and divergences among countries did not change considerably in the last ten years, and the foreseen convergence process has not been achieved.

\section{Discussion}

Public policies have an important impact on people's wellbeing: income, work, environment are all factors that affect the main determinants of quality of life. Therefore, monitoring indicators - such as poverty, employment or greenhouse emissions - policy makers could have measured the modifications of the living conditions of the European populations (Grimaccia and Lima, 2015).

This study shows that - according to the Europe 2020 indicators - in the EU, social and economic disparities have stopped narrowing and poverty and exclusion have increased, including in the richer Member States. The EU27 as a whole shows partial progresses in environmental and education indicators, but it has been unsuccessful in the inclusion indicators, since there have not been significant improvement in the employment levels while the number of people at risk of poverty decreased well below expectations (and increased in some MSs). Furthermore, no effort has been made in investment in Research and Development, failing in the innovation process that could (and should) have been the tool to generate (smart) growth (Ruser and Anheier, 2014).

The European Union, in 2010, set clear development goals - ambitious and measurable. This should have allowed policy makers to follow up on achieving these goals. Analysing the situation 10 years later (but with data that do not take into account - for temporal reasons - the shock due to Covid-19 pandemic) it can be seen that Europe has not achieved its objectives. Looking at the detail of single MSs, apart from virtuous countries such as Sweden and Austria, many MSs did little to achieve the goals that were considered important by the countries themselves.

The use of composite indicators - that seemed the most suitable methodology to analyse the Europe 2020 set of indicators (Stumbriene et al., 2020) - allowed to point out the low share of countries reaching the Strategy goals, and the fact that in 2010 some countries set targets that they had already achieved. Considering the dissimilarity measures, in the ten years under scrutiny, the differences among the countries seemed unchanged.

For the future, UN Sustainable Development Goals certainly identify an important pattern for fair and sustainable development, but the use of more than 200 indicators (some of which are currently not measurable) certainly makes progress more difficult to monitor, and countries less accountable for their development progress efforts.

The eight indicators of the Europe 2020 strategy can still be made subjects of analysis, in order to provide policy makers of well-established measures of development and living conditions, and further analysis could be devoted to the relationship between the EU2020 indicators and other measures of economic growth.

\section{Notes}

Note 1. In the analysis, the data refer to the countries that are MSs of the EU in 2020: Austria, Belgium, Bulgaria, Croatia, Republic of Cyprus, Czech Republic, Denmark, Estonia, Finland, France, Germany, Greece, Hungary, Ireland, Italy, Latvia, Lithuania, Luxembourg, Malta, Netherlands, Poland, Portugal, Romania, Slovakia, Slovenia, Spain and Sweden. 


\section{References}

Alkire, S. (2015). Capability Approach and Well-being Measurement for Public Policy. OPHI Working Paper 94, Oxford University. https://doi.org/10.1093/oxfordhb/9780199325818.013.18

Alkire, S., Foster J. E., Seth, S., Santos, M. E., Roche, J. M., \& Ballon, P. (2015). The Alkire-Foster Counting Methodology. OPHI Working Paper 94, Oxford University. https://doi.org/10.1093/acprof:oso/9780199689491.003.0005

Anand, S., \& Sen, A. (1997). Concepts of Human Development and Poverty: A Multidimensional Perspective. Human Development Papers 1997. New York: United Nations Development Programme. 1-20.

Barder, O., Clark, J., Lepissier, A., Reynolds, L., \& Roodman, A. (2013). Europe beyond aid: assessing European countries' individual and collective commitment to development. Journal of International Development, 25, 832853. https://doi.org/10.1002/jid.2933

European Commission. (2009). GDP and beyond-Measuring progress in a changing world. COM(2009) 433 final. Brussels.

European Commission. (2010). Europe 2020. A strategy for smart, sustainable and inclusive growth. COM(2010). Brussels.

European Commission. (2013). Progress on 'GDP and beyond' actions. SWD (2013) 303 final. Brussels.

European Council. (2010). Presidency Conclusion. Bruxelles

Eurostat. (2019). Smarter, greener, more inclusive? Indicators to support the Europe 2020 strategy. Luxembourg

Fang Z. (2020) The Methods and Tools for Clustering Analysis. Reference Module in Biomedical Sciences, 2020.

Grimaccia, E., \& Lima R. (2015). A territorial dimension for Europe 2020 strategy indicators. Neodemos.info.

Grimaccia, E., \& Rondinella, T. (2018). A novel perspective in the analysis of sustainability, inclusion and smartness of growth through Europe 2020 indicators. In Perna C., Pratesi M., Riuz-Gazen A. (Eds) Studies in Theoretical and Applied Statistics. Springer. https://doi.org/10.1007/978-3-319-73906-9_28

Murtagh, F., \& Legendre, P. (2011). Ward's Hierarchical Clustering Method: Clustering Criterion and Agglomerative Algorithm. https://arxiv.org/abs/1111.6285

OECD, European Union, Joint Research Centre - European Commission (2008). Handbook on constructing composite indicators: methodology and user guide. $\mathrm{OECD}$

Rondinella, T., \& Grimaccia E. (2017). Joint Analysis of Structural Models and Performance: Merging Clustering and Composite Indicators in the Analysis of Europe 2020 Strategy. In Maggino F. (Ed.) Complexity in Society: From Indicators Construction to their Synthesis. Social Indicators Research Series 70. https://doi.org/10.1007/978-3-319-60595-1_13

Ruser, A., \& Anheier, H. K. (2014). The EU's future role on the global stage. Global Policy, 5(1), 58-67. https://doi.org/10.1111/1758-5899.12146

Sen, A. (1983). Poverty and Famines: An Essay on Entitlement and Deprivation. OUP Clarendon Press Oxford. https://doi.org/10.1093/0198284632.001.0001

Sen, A. (2000). A decade of human development. Journal of human development and capabilities, 1(1), 17-23. https://doi.org/10.1080/14649880050008746

Stec, M., \& Grzebyk, M. (2016). The implementation of the Strategy Europe 2020 objectives in European Union countries: the concept analysis and statistical evaluation. Quality \& Quantity, 52, 119-133. https://doi.org/10.1007/s11135-016-0454-7

Steurer, R., \& Hametner, M. (2013). Objectives and indicators in sustainable development strategies: similarities and variances cross Europe. Sustainable Development, 21(4), 224-241. https://doi.org/10.1002/sd.501

Stiglitz, J. E., Sen, A., \& Fitoussi, J. P. (2009). Report by The Commission on the Measurement of Economic Performance and Social Progress. Paris

Stumbriene D., Camanho A. S., \& Jakaitiene, A. (2020). The performance of education systems in the light of Europe 2020 strategy. Annals of operational research, 288, 577-608. https://doi.org/10.1007/s10479-019-03329-5

World Bank. (2017). Monitoring Global Poverty: Report of the Commission on Global Poverty. Washington, DC: World Bank. 
Yu, C. H. (2012). Beyond Gross National Product: An Exploratory Study of the Relationship between Program for International Student Assessment Scores and Well-being Indices. Review of European Studies, 4(5), 2012. https://doi.org/10.5539/res.v4n5p119

\section{Copyrights}

Copyright for this article is retained by the author(s), with first publication rights granted to the journal.

This is an open-access article distributed under the terms and conditions of the Creative Commons Attribution license (http://creativecommons.org/licenses/by/4.0/). 